\title{
First data of the Colombia Lightning Mapping Array - COLMA
}

\author{
Jesús Alberto López, Joan Montanyà, Oscar van der \\ Velde, David Romero \\ Department of Electrical Engineering \\ Universitat Politècnica de Catalunya \\ Terrassa (Barcelona), Spain \\ jesus.alberto.lopez@estudiant.upc.edu
}

\begin{abstract}
The first data set of VHF lightning mapping using a Lightning Mapping Array system - LMA in a tropical region is presented in this paper. Six sensors were installed at the north of Colombia near Santa Marta city. Since the installation of the LMA network in 2015, up to 7000 intra-cloud (IC) discharges from September to November 2015 have been analyzed. The data suggests that, the electrical charge distribution in tropical thunderstorms shows higher vertical development reaching higher altitudes compared to thunderstorms in temperate latitudes.
\end{abstract}

Keywords-Lightning Mapping Array - LMA; Electrical charge structure; Tropical storm.

\section{INTRODUCTION}

Colombia is a tropical country with a series of topographic and climatology complex conditions. The mountainous environment given by branched of the Andes in three mountainous chains (eastern, central and western) make an orographic system of hills, valleys and foothills that being at the south of Colombia and cross the entire country with a broad altitude range (Figure 1) and several climatic conditions. These orographic and climatic conditions have been taken for delimited the land area in five natural regions: Pacífico, Caribe, Andes, Orinoquía and Amazonía [1].

Additionally, the influence of the Intertropical Convergence Zone - ITCZ (given by the northeast and southeast trade winds), makes a spatial, temporal and orographic relationship with the lightning parameters [2]. For example, the dependence of the Ground Flash Density - GFD with the latitude has been studied recently in tropical and temperate regions [3-4]. In Colombia, the high values of GFD are principally located in foothills, between 500 to 1000 m.a.s.l [5], and the lightning seasonal evolution is represented by unimodal and bimodal frequency distribution [2]. This means that, in some regions in Colombia, the lightning activity peaks twice per year.

Lightning parameters and worldwide thunderstorm distribution have been determined thanks to the capability of ground-based and space-based Lightning Location Systems LLS among other systems or techniques. Although lightning observations from satellites are restricted to a short time

\author{
Daniel Aranguren ${ }^{1}$, Horacio Torres ${ }^{1}$, John Taborda ${ }^{2}$, \\ Joaquin Martinez ${ }^{2}$ \\ ${ }^{1}$ Keraunos Company, Bogotá, Colombia \\ ${ }^{2}$ Universidad del Magdalena, Santa Marta, Colombia \\ 11daranguren@keraunos.co, 2jatabordag@gmail.com
}

measurements and ground-based sensors only cover small areas of land, the popularization of LLS has allowed to provide more information about lightning parameters associated with regional and temporal characteristics. In fact, as has been reported by several authors [2][5][6], one region with the highest lightning activity in the world is located in the tropical zone "Catatumbo" composed by the upper area of the Magdalena river valley in Colombia and the Maracaibo region in Venezuela, with a GFD up to 53 flashes $/ \mathrm{km}^{2}$ - year such as shown in Fig. 2 (Ground Flash Density map).

Thanks to the advanced system of lightning detection for scientific research, it is possible to obtain much more information of the thunderstorm activity. The Lightning Mapping Array (LMA) system [9] is a ground-based system that detects VHF lightning impulses and allows us to obtain three-dimensional locations of lightning sources emitted by leaders. The LMA system is thoroughly used and helps to characterize thunderstorm such as, lightning leader propagation, inferring electrical charge structure, distinguish cloud regions (e.g. convective or stratiform), thunderstorm intensity, etc. Currently, most of the LMA systems operate in temperate zones (e.g. US and Europe), and few measurements have been developed in tropical areas. Thanks to the LMA networks, it has been possible to identify and analyze complex electrical charge distributions and the evolution of lightning [16] in different type of thunderstorms.

Nowadays, a new field of the study in physics and engineering sciences has been developed around of the highenergy emissions produced by transient phenomena related with thunderstorm activity [7-8]. These phenomenon are characterized by the high dissipate energy at higher atmosphere (above to the troposphere), and have been classified in two transients group: Transient Luminous Events (TLEs) and Terrestrial Gamma-ray Flashes (TGFs). Currently, it is thought that TGFs are produced by certain electrical properties of thunderstorms such as its charge structure, vertical potential distribution and electric field conditions. Space-based detections of global TGFs distribution have shown the tropical regions as the most active zones of TGFs. Fabro et al. [8] presented a recent analysis of global TGFs distribution, where South America was characterized by a high value of TGFs detections. 
This paper presents the first data set of VHF 3D lightning measurements obtained from the recent LMA system installed in Santa Marta-Colombia. Some electrical properties of thunderstorms activity measured from October to November 2015 are analyzed and discussed. The electrical charge distribution, altitude of lightning sources and lightning rates are presented. Some of these findings are compared with lighting measures obtained in mid latitudes using similar methods.



Figure 1. Colombian topographic.

\section{LIGHTNING ACTIVITY IN COLOMBIA}

Several studies about lightning parameters have been done during the last years in Colombia. The Keraunic Level-KL was the first parameter published in 1990 by the Colombian Weather Service and the National University of Colombia [2]. This parameter helped to find the temporal and spatial lightning behavior in Colombia, where The Magdalena and Cauca rivers valleys, Catatumbo, Pacífico and other regions were clearly defined as higher lightning activity areas with more than 100 thunderstorms days per year. At the same time, the thunderstorms seasonal occurrence at the centre of Colombia defined by bi-modal behavior was founded.

On the other hand, Younes [10] in 2002 presented the first Ground Flash Density-GFD map obtained from the Colombian Lightning Location Network - RECMA. Values between 20 to 30 flashes $/ \mathrm{km}^{2}$-year were estimated and the spatial distribution of thunderstorm previously published was confirmed. In 2010 a new GFD map was published by Gallego [11], where new regions and values of GFD were identified. Figure 2 shows the latest GFD map published by Aranguren et al. [12] using the Total Lightning Location Network - LINET recently installed in Colombia (since 2011). These new results were consistent with the reports above mentioned, and provided new information about latitudinal and spatial behavior of thunderstorms in Colombia. Maximum values of 60 flashes $/ \mathrm{km}^{2}$ year were computed. The highest lightning active zones were correlated with topographic conditions, such as foothills and valleys. This GFD map allowed at same time to obtain new observations of the lightning activity over Maracaibo Lake in Venezuela. This zone is considered as one of the most higher thunderstorm areas around the world, and the results were consistent with several reports made by others authors [13-14].

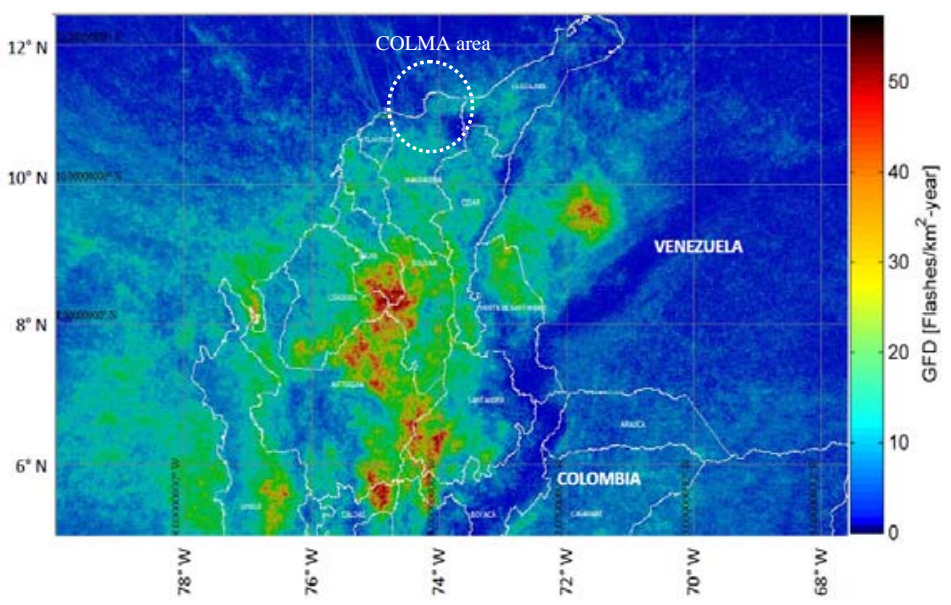

Figure 2. Ground Flash Density map derived form LINET network in Colombia and Venezuela. Adaptaded form [6].

Additionally, it was possible to define the noticeable dependence of the thunderstorms activity with altitudinal variation as shown in Fig. 3. Where, the GFD decreases with the increase of the altitude, and the maximum average value was reported in areas up to 1000 m.a.s.l.

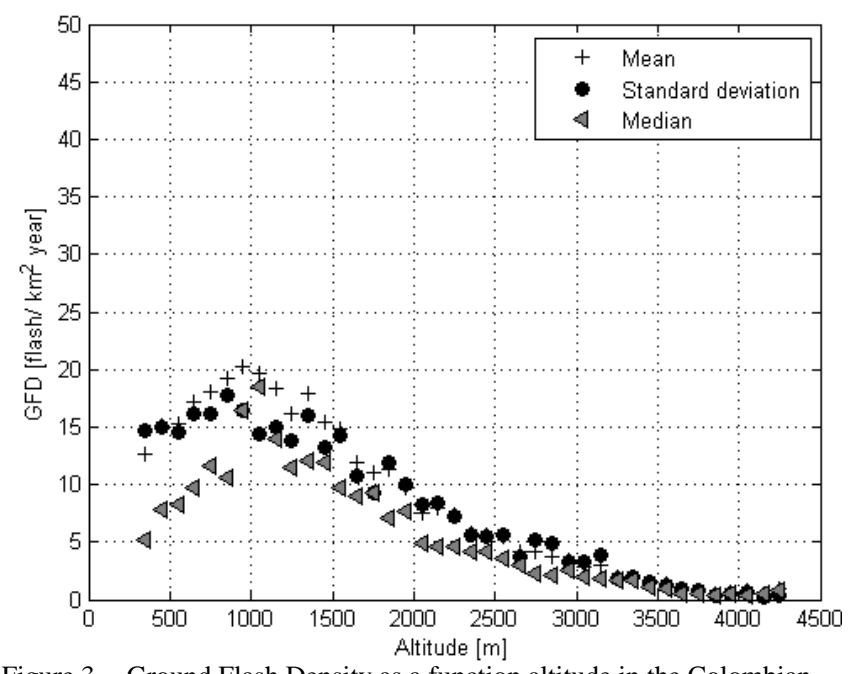

Figure 3. Ground Flash Density as a function altitude in the Colombian mountainous zones. Adapted from Aranguren et al. [12]

On the other hand, the area enclosed by dashed-circle in the Fig. 2, shows the coverage area of the LMA network such as detailed below. This region is delimited by the Sierra 
Nevada de Santa Mar

extension given by Atlantic ocean. The GFD of 15-20 flashes/km2-year was estimated in the LMA area, and the Keraunic Level is approximately of 100 thunderstorm days per year.

\section{COLOMBIA LIGHTNING MAPPING ARRAY}

In April 2015 a Lightning Mapping Array-LMA network was installed in Colombia (COLMA) in the frame of Atmosphere Space Interactions Monitor-ASIM mission [15]. The LMA system detects VHF radio emissions sources from lightning discharges, in our case signals between 60 to $66 \mathrm{MHz}$ band are detected by base-ground sensors, and measure the magnitude and arrival times of radio noises produced by lightning leaders. Each individual flash is represented by several lightning sources and can be reconstructed through lightning maps in three-dimensional location [9].

The COLMA network is composed by six VHF detectors with a baseline between 5 to 20 kilometers. The area of interest is located at north of Colombia, it covers a small littoral zone of the Atlantic ocean, the Santa Marta city and the western foothills of the Sierra Nevada de Santa Marta mountain, the most highest and isolated mountain in Colombia with a maximum altitude value of 5700 m.a.sl. Additionally, this mountain have an imposing altitudinal gradient, given by the change from the sea level to maximum elevation given by 5700 m.a.s.l in only 45 kilometers of distance. Figure 4 shows the COLMA coverage area and its VHF stations.

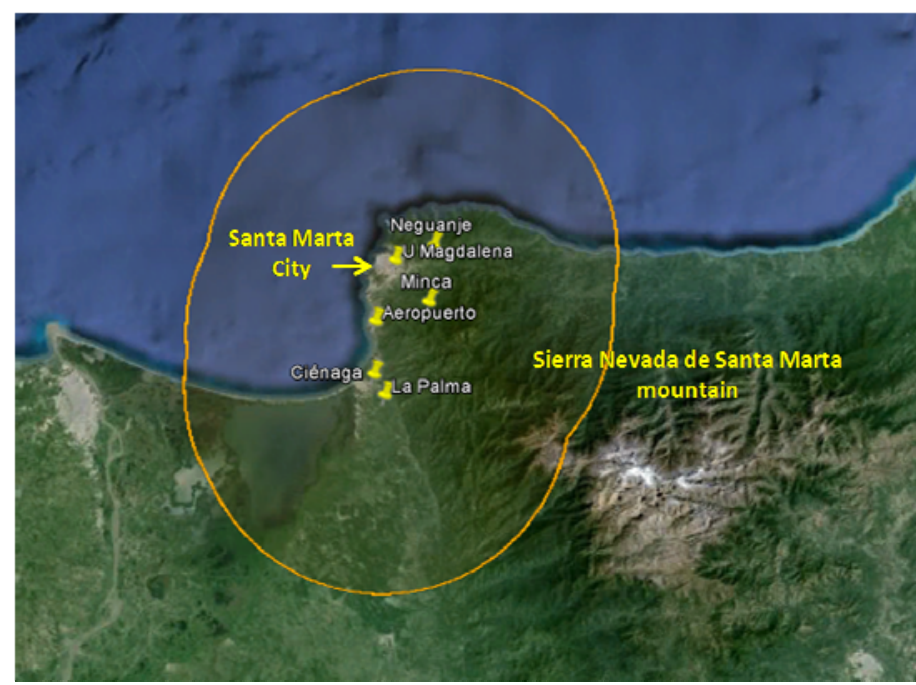

Figure 4. Colombia Lightning Mapping Array coverage area

\section{DATA}

Between September to November 2015, a total of 7000 individual flashes and up to 481202 sources were registered by the COLMA network. These records are the first set VHF total lightning mapping obtained in tropical zones. At the same time, records from 2011 to 2015 were employed from the ELMA data (Ebro Lightning Mapping Array) at the north-east coast of Spain in order to obtain a relationship between electrical charge onference Qn Lightning Protection (IGLP) by the Total Lightning Location Network LINET [12] operated by Keraunos company in Colombia. Nonetheless this kind of information were used by simple inter-comparators in time scale.

\section{RESULTS}

\section{A. Observations of the COLMA network}

Two observations of the COLMA network are shown in Fig 5 and Fig 6. The first case shows an individual flash measured on 8 June 2015 and second provide an example of ten minutes of lightning registered on 11 November de 2015.

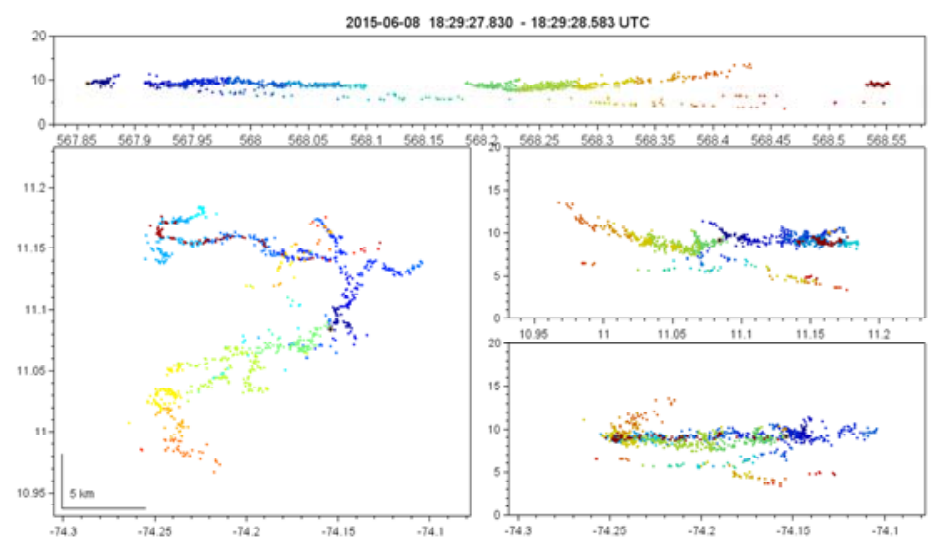

Figure 5. Example of temporal and spatial COLMA flash detected. The top panel is altitude versus time (seconds) by an individual flash. The left side panel is a plant view. The right panels show the sources location (latitude and longitude) versus altitude $(\mathrm{km})$

From Fig 5, an individual flash was initiated at $10 \mathrm{~km}$ of height. Leaders propagated into the upper and lower active regions located at 15 and $3 \mathrm{~km}$ of height respectively. The flash duration computed as the time difference between the last and the first source was 700 milliseconds. Using the maximum distance of the branch, the length of the flash resulted in $20 \mathrm{~km}$ of length approximately.

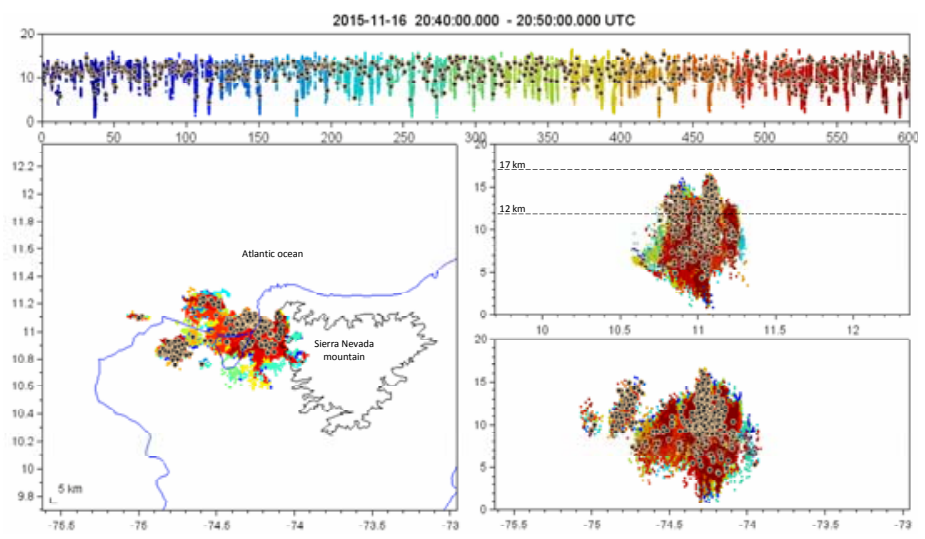

Figure 6. Example of lightning sources observation from COLMA network. The top panel is altitude versus time (seconds) for an interval of 10 minutes. The left side panel show a plant view of sources locations. The right panels show the sources location (latitude and longitude) versus altitude (km). 
Figure. 6 shows ten minutes interval of lightning by the COLMA network. During this interval there were detected a total of 48610 radio emissions sources. Temporal lightning occurrence and its height sources are shown at the top of the figure. The lightning sources coordinates and the cross-section (latitude, longitude as a function of altitude) are shown at the bottom view. During this ten minutes period of the COLMA detections, the lightning sources were detected between 3 to 17 $\mathrm{km}$ of height, with a rate of 81 flash sources per second and the median altitude was calculated to be at $10.3 \mathrm{~km}$ of height.

\section{B. Electrical charge structure}

The electrical charge structure was estimated according to the 3-dimensional lightning sources locations by the COLMA network using a simple inspection of its high distribution. Nonetheless, there are different techniques in the analysis of storm charge structure [16]. In this case, Fig 7 shows the median height distribution of the lightning location.

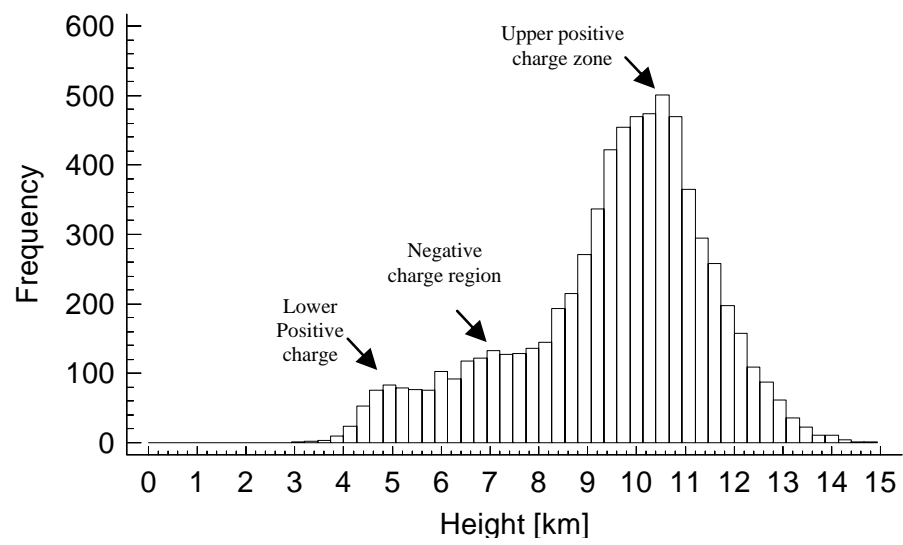

Figure 7. Median height distribution of the lightning sources from COLMA network (low positive charge center and main negative regions are stimated from individual flashes).

According to the height distribution (see Fig. 7) and the analysis of individual flashes, it is clear that the upper positive region ranges from 9 to $15 \mathrm{~km}$. Leader activity below $9 \mathrm{~km}$ suggest a tripolar electrical charge structure. A complementary analysis was developed using both height distributions of Colombia COLMA and Spain ELMA datasets such as shown in Fig 8.

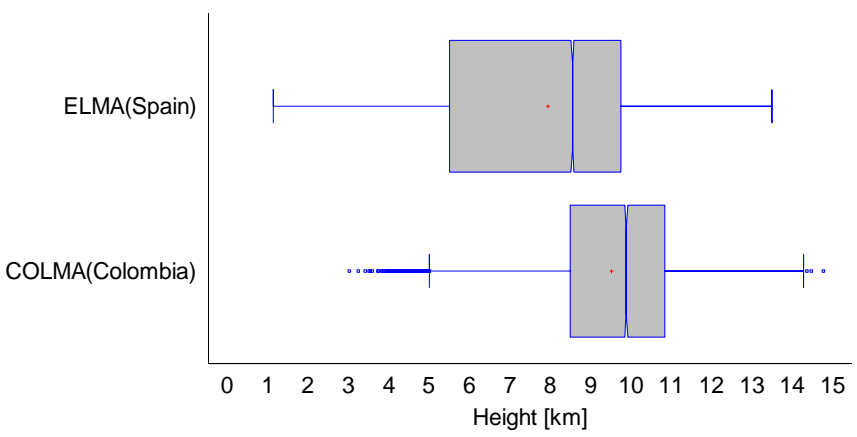

Figure 8. Height distributions of Colombia COLMA and Spain ELMA
The box plots shows that, the majority of flashes have a typical altitude at about $8 \mathrm{~km}$ in the case of Spain, and $10 \mathrm{~km}$ for Colombia.

\section{Maximum sources altitude}

The maximum height of the lightning sources was analyzed as a measure of the vertical extension in the tropical storms. In our case, Fig 9 shows the cumulative distribution function for the maximum altitude of the lightning sources detections.

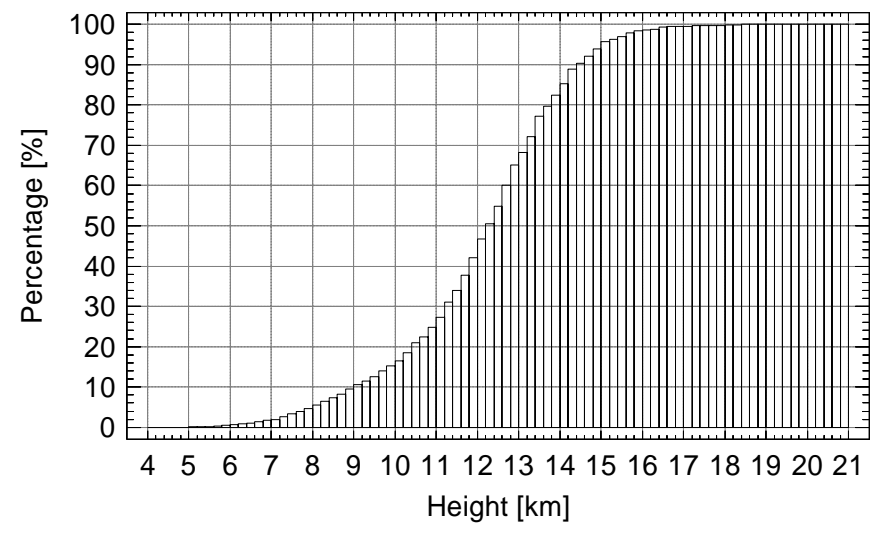

Figure 9. Acumulatopn distribution of maxium altitude of lightning sources.

The distribution shows that, 50 percent of the flashes have activity above $12.5 \mathrm{~km}$ (where the upper positive charge region was identified). As well as, 70 percent of these flashes have altitudes above 13.5 kilometers of altitude. Only 10 percent of the lightning sources are detected between $14 \mathrm{~km}$ to $19 \mathrm{~km}$.

\section{CONCLUSION}

We present here the first data set of the 3-dimensional VHF lightning measurements in tropic areas obtained from LMA network installed in Santa Marta-Colombia. A total of 700 individual flashes from September to November 2015 have been analyzed, and up to 481000 sources have been proceeded. The findings suggest that, the tropical storm have a higher vertical development, where lightning leaders can propagate up to $18 \mathrm{~km}$ of height (see Fig. 6-8). According to the median height distribution of lightning sources, the majority of leader flashes in Colombia initiated at about $10 \mathrm{~km}$ of height, more than $2 \mathrm{~km}$ above compared to the storm at the ELMA in Spain, and the its vertical extension have been identified between 3 to $15 \mathrm{~km}$. Regarding the structure of electrical charge, a tripolar distribution has been identified, with values centered at 5, 7.5 and $10 \mathrm{~km}$ of height by the lower positive charge region, midlevel negative charge region and upper positive charge region respectively.

The information present in this paper has many implications because, the COLMA network is the first VHF 3dimensional system installed in the tropical regions and this type of information will allow to analyze the electrical properties of tropical storms such as, spatial distribution, intra cloud ratio, duration, altitude of the electrical charge, lightning leader information, thunderstorm evolution and the conditions 
favorable for the production of Terrestrial Gamma ray Flashes TGF in tropical zones.

\section{ACKNOWLEDGMENT}

This work was supported by research grants from the Spanish Ministry of Economy and the European Regional Development Fund (FEDER): MINECO AYA2011-29936C05-04 and (MINECO/FEDER) ESP2013- 48032-C5-3-R and (MINECO/FEDER) ESP2015-69909-C5-5-R.

\section{REFERENCES}

[1] C. Castaño, A. Soto, C. Botero. "Colombia first national Communication to the United Nations framework convention on Climate Change", Annual Report. The Colombian Weather Service. Bogotá, 2011.

[2] H. Torres. "El rayo: mitos, leyendas ciencia y tecnología”. National University of Colombia, vol1, Bogotá-Colombia, pp, 120-200, 2002.

[3] V. Bourscheidt, O. Pinto, K.P. Naccarato, I.R.C.A. Pinto, "The influence of topography on the cloud-to-ground lightning density in South Brazil” Atmospheric Research 91, pp. 508-513, Brazil, 2009.

[4] W. Schulz, G. Diendorfer. "Lightning Characteristics as a Function of Altitude Evaluated from Lightning Location Network Data" International Conference on Lightning and Static Electricity, Toulouse, France, 1999.

[5] D. Aranguren, J. López, J. Inampués, H. Torres and H. D. Betz, “Cloudto-ground ligthning activity in Colombia and the influence of topography”, Lightning Protection (ICLP), 2014 International Conference o, Shanghai, 2014, pp. 1850-1855.

[6] H. Torres, E. Pérez, C. Younes, D. Aranguren, J. Montaña, J. Herrera, "Contribution to Lightning Parameters Study Based on Some American Tropical Regions Observations”. IEEE Journal of Selected Topics in Applied Earth Observations and Remote Sensing, vol. 8, no. 8, August 2015.

[7] Carlson, B. E., Lehtinen, N. G., Inan, “Constraints on terrestrial gamma ray flash production from satellite observation”, Geophysical Research Letters, Vol. 34, L08809, April 2007.
[8] F. Fabró, J. Montanyà, M. Marisaldi, O. van der Velde, F. Fuschino, "Analysis of global Terrestrial Gamma Ray Flashes distribution and special focus on AGILE detections over South America” Journal of Atmospheric and Solar-Terrestrial Physics, Volume 124, Pages 10-20, March 2015.

[9] W. Rison, R.J. Thomas, P.R. Krehbiel, T. Hamlin, and J. Harlin, “A GPS-based Three-Dimensional Lightning Mapping System: Initial Observations in Central New Mexico”, Geophysical Research Letters, vol. 26, N0. 23, Pages 3573-3576, December 1999.

[10] Younes, C. "Evaluación de parámetros del rayo con mediciones terrestres y satelitales para Colombia”. Master's Thesis, National University of Colombia, 2002.

[11] Gallego J. "Parámetros de las Descargas Eléctricas Atmosféricas en Colombia”. Undergraduate Thesis, National University of Colombia, Medellín, 2010.

[12] D. Aranguren, J. Inampués, J. López, A. Tibaduiza, F. Casas, H. Torres, H. Betz, "Colombian Total Lightning Detection Network and early detection of failure risks for power systems”. SICEL2013, Medellín, Cololmbia.

[13] H. J. Christian, R. J. Blakeslee, S. J. Goodman. "The detection of lightning in geostationary orbit ”. J. Geophys. Res. 94:13 329-37. 1989.

[14] Christian, H. J. and Latham, J. (1998), Satellite measurements of global lightning. Q.J.R. Meteorol. Soc., 124: 1771-1773. December 2006.

[15] Brochure:ASIM on the International Space Station. http://www.terma.com/space/the-asim-observatory/

[16] S. A. Weiss, W.D. Rust, D. R. MacGorman, E. C. Bruning, P. R. Krehbiel, Evolving Complex Electrical Structures of the STEPS 25 June 2000 Multicell Storm, Mon. Wea. Rev., 136, 741-756. February, 2008. 